\title{
A study on clinical profile of patients presenting with adverse drug reaction: a hospital based prospective observational study
}

\author{
Ram Singh ${ }^{1}$, Jatinder Kumar Mokta ${ }^{1}$, Kiran Mokta ${ }^{2}$, \\ Surinder Thakur ${ }^{1}$, Rajesh Bhawani ${ }^{1}$, Ramesh ${ }^{3}$ *
}

${ }^{1}$ Department of Medicine,

${ }^{2}$ Department of Microbiology,

${ }^{3}$ Department of Pharmacology,

Indira Gandhi Medical College

Shimla, Himachal Pradesh, India

Received: 15 July 2019

Accepted: 16 August 2019

*Correspondence to:

Dr. Ramesh,

Email: rameshgulepa9674

@ gmail.com

Copyright: (C) the author(s), publisher and licensee Medip Academy. This is an openaccess article distributed under the terms of the Creative Commons Attribution NonCommercial License, which permits unrestricted noncommercial use, distribution, and reproduction in any medium, provided the original work is properly cited.

\begin{abstract}
Background: The aim of the study was to study the clinical profile of patients presenting with adverse drug reaction.

Methods: The study was conducted in the Department of Medicine, IGMC Shimla from 01 July 2015 to 30 June 2016. A total of 129 patients were included in this study. A detailed history was taken followed by examination of patients. The routine investigations were done and special investigations as per need. For analysis patients detail, suspected drugs and the adverse drug reactions caused by them were used.

Results: Bleeding from various sites was the most common event (39.5\%), followed by symptomatic hypoglycemia $22.5 \%$ of events and symptomatic hyponatremia in $16.3 \%$ events. Amongst various drug classes anticoagulants were the most commonly involved drug class followed by oral hypoglycaemic agents, diuretics and antiplatelets. Type A was predominant ADR constituting $(97.7 \%)$ of total ADRs and only $(2.3 \%)$ of ADRs were of type B. After causality assessment, majority $86(66.6 \%)$ were probable related and large number $127(98.3 \%)$ of ADRs were serious which recovered after hospitalization.

Conclusions: Our study revealed that ADRs are frequent and are easily recognized in clinical practice and are mostly preventable. Most ADRs are due to the use of drugs with high toxicity for example, warfarin often results in bleeding. It also shows that careful drug monitoring in hospitals may lead to reduction of many such ADRs, suggesting that some type A, ADRs may be due to inadequate monitoring of therapies and doses. This study will aid the development of interventions to reduce the impact of ADRs in hospital inpatients.
\end{abstract}

Keywords: Adverse drug reaction, Gastrointestinal bleeding, Anticoagulants

\section{INTRODUCTION}

Drugs are the most common medical interventions, primarily used to relieve sufferings. But it has been recognized long ago that drug themselves can prove fatal; as the saying rightly goes "Drugs are double edged weapons". Drug toxicity is a major limitation in providing health care to patients at a global level. It affects patient's recovery as well as the economy of health care. With the increase in production of various pharmaceutical products and newer drugs being introduced every year adverse drug reaction (ADR) is becoming more important due to its increased incidence and financial implications. ${ }^{1}$

The World Health Organization defined an adverse drug reaction as noxious, unintended and which occurs at dosages normally used in human beings for prophylaxis, diagnosis and therapy for the disease or for the modification of the physiological function. ${ }^{2}$

In the year 1977, Rawlins and Thompson, classified ADR into type A and type B which was further expanded from type $\mathrm{C}$ to type $\mathrm{G}$ by Edwards and Aronson (2000). ${ }^{3,4}$ 
Adverse drug reactions are responsible for $5 \%$ of all hospital admissions. It is seen in $10-20 \%$ of patients who are admitted in hospitals. ${ }^{5-8}$ Among hospitalized patients, an overall incidence of serious and fatal ADR was $6.7 \%$ and $0.32 \%$ respectively. ${ }^{9}$ In the study of adverse drug reaction it is required to identify the various risks for ADRs, common drugs that lead to ADRs, therapeutic class of those drugs, usage of concomitant medications if any and demographic profile of patients should also be known. The knowledge of ADR specific data such as type of reaction, system affected and probable causes will be of great help in minimizing ADRs. ${ }^{10}$

When an adverse drug reaction occurs during or after drug treatment, it may be a result of the drug, or the disease for which the drug was taken, or it may have another, unrelated cause.

Lack of studies on ADRs at national level along with easy availability and indiscriminate use of drugs had developed a scope for more studies which will contribute in planning and formulating policies in public health in this field. When an adverse reaction is suspected, it is important to try to assess how likely it is that symptoms have occurred because of a drug. Clinical trials detect only the most common adverse effect. Post marketing surveillance or pharmacovigilance involves observational studies of patients who receive drugs in the course of clinical practice.

The present study aims to identify, characterize and analyze the pattern of ADRs in tertiary care hospital. This study may be useful in identifying and minimizing various ADRs, also it may help the clinicians to handle with ADRs more efficiently.

\section{METHODS}

The study was conducted in the department of Internal medicine of Indira Gandhi Medical College and hospital (IGMC), Shimla from 01 July 2015 to 30 June 2016. It was a prospective observational study involving 129 patients who fulfilled the inclusion criteria: Age above 18 years among all patients, all OPD patients and indoor patients of department of medicine with ADR and all patients giving written consent. The exclusion criteria for this study were: Age below 18 years, patients with poisoning, patients with drug overdose and patients refusing for written consent.

The study population was subjected to focused history to record the information related to demographic profiles, presenting complaints, background history of diabetes, hypertension, medication allergy and comorbid conditions as per proforma. All patients were subjected to general physical examination and systemic examination followed by relevant investigations such as complete haemogram, renal function test, liver function test, electrolytes, upper and lower gastrointestinal endoscopy,
X-ray chest, ultrasonography abdomen, computed tomography scan and magnetic resonance imaging.

The adverse drug reactions were analyzed under the following categories:

- Type of reaction based on Rawlins \& Thomson criteria as Type-A and Type-B.

- Severity based on the classification system of WHO and system of Hartwig et al into:

\section{Mild}

Level 1: The ADR requires no change in treatment with the suspected drug.

Level 2: The ADR requires that the suspected drug be withheld, discontinued or otherwise changed. No antidote or other treatment is required, and there is no increase in length of stay.

\section{Moderate}

Level 3: The ADR requires that the suspected drug be withheld, discontinued or otherwise changed, and/ or an antidote or other treatment is required. There is no increase in length of stay.

Level 4: (i) Any level 3 ADR that increases length of stay by at least one day. (ii) The ADR is the reason for admission.

\section{Severe}

Level 5: Any level 4 ADR that requires intensive medical care.

Level 6: The ADR causes permanent harm to the patient

Level 7: The ADR either directly or indirectly leads to the death of the patient.

\section{Seriousness}

The reaction was deemed serious when the patient outcome was either of the following; (a) death, (b) lifethreatening (real risk of dying), (c) hospitalization (initial or prolonged), (d) disability (significant, persistent or permanent), (e) congenital anomaly and (f) required intervention to prevent permanent impairment or damage.

\section{Assessing causality}

The causality relationship with the drug was established using the WHO probability scale. Accordingly the causality was categorized as; (a) certain - good timing, no other cause, withdrawal response plausible, rechallenge, "definitive"; (b) probable - good timing, other cause unlikely, withdrawal; (c) possible - good timing, other 
causes; (d) unlikely - poor timing, other causes more likely and (e) un-assessable - insufficient or contradictory information.

\section{Outcomes}

Outcome of the event was defined as; (a) fatal, (b) continuing, (c) recovering, (d) recovered and (e) unknown.

\section{RESULTS}

\section{Demography}

The age of patients presenting with ADR ranges from 21 years to 94 years with mean age of $56.9 \pm 15.61$ years. Geographically, a total of $106(82.2 \%)$ patients were from rural area and $23(17.8 \%)$ patients were from urban area.

\section{Clinical events}

In our study, bleeding from various sites was the most common event presenting in $51(39.5 \%)$ cases, out of which upper G.I bleeding was the most common $26(20.2 \%)$ followed by other sites of bleeding as shown in Table 1. Hypoglycaemia $29(22.5 \%)$ represented the second most common event in our study, it was followed by Symptomatic hyponatremia in 21 (16.3\%), and hepatitis in $7(5.4 \%)$ cases. Seizure and erosive gastritis constituted $3(2.3 \%)$ events each. Cushing's syndrome, bradycardia, pancytopenia and erosive gastritis were documented in $2(1.6 \%)$ events each. These events were followed by erythema nodosum, acute liver failure, sensory motor neuropathy, bluish discoloration of nails, severe dapsone hypersensitivity syndrome, angioedema, tardive dyskinesia, gynaecomastia and psychosis in 1 $(0.8 \%)$ event each (Table 1$)$.

Table 1: Various sites of bleeding as an adverse drug reaction.

\begin{tabular}{|lll|}
\hline S. No. & Events & $\begin{array}{l}\text { Number of } \\
\text { cases }(\%)\end{array}$ \\
\hline $\mathbf{1}$ & Upper G.I bleeding & $26(20.2)$ \\
\hline $\mathbf{2}$ & Haematuria & $7(5.4)$ \\
\hline $\mathbf{3}$ & Subdural haemorrhage & $5(3.9)$ \\
\hline $\mathbf{4}$ & Intraparenchymal haemorrhage & $3(2.3)$ \\
\hline $\mathbf{5}$ & Intraabdominal haemorrhage & $2(1.6)$ \\
\hline $\mathbf{6}$ & Vaginal bleeding & $2(1.6)$ \\
\hline $\mathbf{7}$ & Nasal bleeding & $2(1.6)$ \\
\hline $\mathbf{8}$ & Hemarthrosis & $2(1.6)$ \\
\hline $\mathbf{9}$ & Hematoma arm & $1(0.8)$ \\
\hline $\mathbf{1 0}$ & Lower gastro intestinal bleed & $1(0.8)$ \\
\hline
\end{tabular}

Amongst various classes of drugs anticoagulants were involved in $33(25.6 \%)$ events, oral hypoglycaemic agents in $25(19.4 \%)$ events, diuretics in $17(13.2 \%)$ events, antiplatelets in $13(10.1 \%)$ events, antibiotics in $11(8.5 \%)$ events, insulins in $7(5.4 \%)$ events, non-steroidal antiinflammatory drugs in $5(3.9 \%)$ events, angiotensin receptor blockers in $4(3.1 \%)$ events, beta blockers and antipsychotics in $3(2.3 \%)$ events each. Fibrinolytics, immunomodulators and steroids were involved in 2 $(1.5 \%)$ of events each and anticonvulsants and statins in 1 $(0.8 \%)$ event each (Table 2$)$.

Table 2: Various clinical events of ADRs and suspected medication(s).

\begin{tabular}{|c|c|c|c|}
\hline S. No. & Clinical events of ADRs & Number of cases & Suspected medication \\
\hline 1. & Bleeding from various sites & $51(39.5 \%)$ & $\begin{array}{l}\text { Warfarin } 26(20.2 \%) \text {, aspiran/clopidogrel } 8(6.2 \%) \\
\text { Acitrome } 6(4.7 \%) \text {, aspirin } 3(2.3 \%) \text { clopidogrel } 2(1.3 \%) \text {, } \\
\text { streptokinase } 2(1.3 \%) \text {, alteplase } 2(1.3 \%) \text {, dabegatran } 2 \\
(1.3 \%) \text {, }\end{array}$ \\
\hline 2 & Hypoglycaemia & $29(22.5 \%)$ & $\begin{array}{l}\text { Glimepiride } 17(13.2 \%) \text {, insulin-regular } 3(2.3 \%) \text {, insulin- } \\
\text { mix (30:70) } 3(2.3 \%) \text {, aspart insulin } 2(1.5 \%) \text {, combination } \\
\text { of glimepiride and metformin } 2(1.5 \%) \text {, combination of } \\
\text { gliclazide and metformin } 1(0.8 \%) \text {, combination of } \\
\text { glimepiride, metformin and pioglitazone } 1(0.8 \%) \text {, }\end{array}$ \\
\hline 3. & Symptomatic hyponatremia & $21(16.3 \%)$ & $\begin{array}{l}\text { Chlorthalidone } 6(4.7 \%) \text {, torsemide } 6(4.7 \%) \text {, } \\
\text { spiranolactone } 3(2.3 \%) \text {, hydrochlorthiazide } 3(2.3 \%)\end{array}$ \\
\hline 4. & Hepatitis & $7(5.4 \%)$ & ATT $6(4.7 \%)$, indomethacin $1(0.8 \%)$ \\
\hline 5. & Seizure & $3(2.3 \%)$ & $\begin{array}{l}\text { Zidovudine } 1(0.8 \%) \text {, linizolid } 1(0.8 \%) \text {, metronidazole } 1 \\
(0.8 \%) \text {. }\end{array}$ \\
\hline 6. & Erosive gastritis & $3(2.3 \%)$ & Diclofenac sodium $3(2.3 \%)$ \\
\hline 7. & Others & $15(11.6 \%)$ & $\begin{array}{l}\text { Telmesarten } 3(2.3 \%) \text {, metoprolol } 3(2.3 \%) \text {, propranolol } 1 \\
(0.8 \%) \text {, prednisolone } 1(0.8 \%) \text {, azathioprine } 1(0.8 \%) \text {, } \\
\text { dapsone } 1(0.8 \%) \text {, halopridol } 1(0.8 \%) \text {, risperidone } 1 \\
(0.8 \%) \text {, atorvastatin, clomipramine, sulfamethoxazole }+ \\
\text { trimethprim } 1(0.8 \%) \text { each }\end{array}$ \\
\hline
\end{tabular}


Top five drugs causing ADRs in our study were warfarin, glimepiride, combination of aspirin+clopidogrel, acitrome and insulin. As per WHO criteria, 3 cases reported as fatal, these were anaphylaxis, laryngospasm and nephrotoxicity while $126(97.6 \%)$ cases were reported as recovered (Table 3). Among all ADRs 126 (97.7\%) were of type A and only $3(2.3 \%)$ patients were of type B. In terms of severity, $23(17.8 \%)$ ADRs were mild in severity, $52(40.3 \%)$ ADRs were moderate and 54 (41.8\%) ADRs were severe in nature. As far as seriousness is concerned, $127(98.4 \%)$ were serious and were hospitalized, death occurred in $3(2.3 \%)$ cases, 19 (14.7\%) ADRs were life threatening and 2 (1.5\%) ADRs were non-serious thus treated on OPD basis. As per WHO causality scale $36(27.9 \%)$ ADRs were definitely related, $86(66.6 \%)$ ADRs were probable related and $7(5.4 \%)$ ADRs were possible and none were unlikely related.

\section{Table 3: Outcome of ADR.}

\begin{tabular}{|lllll|}
\hline \multirow{2}{*}{ Outcome } & Fatal & \multicolumn{3}{c|}{ Recovered } \\
& Number(n) & \% & Number(n) & \% \\
\hline Female & 1 & 0.8 & 62 & 48 \\
\hline Male & 2 & 1.5 & 64 & 49.6 \\
\hline Total & 3 & 2.3 & 126 & 97.6 \\
\hline
\end{tabular}

\section{DISCUSSION}

Adverse drug reactions proved to be a major and a common health hazard in present day medical practices. It has become an utmost important to keep oneself updated with the latest trends, while prescribing medicines. All prescribers need to be vigilant regarding ADRs and consequently management of those ADRs as it causes a huge human suffering in terms of mortality, morbidity and health care costs. The present study was conducted in one hundred and twenty nine patients with adverse drug reactions over a period of one year. Out of one hundred and twenty nine patients, $68(52.7 \%)$ patients were $(\geq 60$ years) and $61(47.3 \%)$ were (<60 years) of age. Amongst 129 patients $63(49 \%)$ were females and $66(51 \%)$ were males with male to female ratio of $1.04: 1$ which was in accordance with previous studies conducted by Kinjal et al, Raut et al with male to female ratio of $1.38: 1$ and 1.08:1 respectively. ${ }^{11,12}$

In our study, gastrointestinal bleeding was the most common site of bleeding seen in $20.2 \%$ cases and is in accordance with previous studies conducted by Onder et al, Raut et al, Sriram et al and Suh et al which exhibited gastrointestinal bleeding in 19\%, 25.87\%, 37\% and $24 \%$ cases respectively. ${ }^{13-15}$ In our study, hypoglycaemia was the second most common ADR which is in accordance with study done by Raut et al, in which endocrine and metabolic system was involved in $22.37 \%$ cases. $^{12}$ Hyponatraemia was mostly due to diuretic use and was the third most common ADR reported in our study. Events of gastrointestinal system were followed by endocrine system (hypoglycaemic events) which might be because of the fact that this study was conducted in medicine department only.
In the study by Munir et al most common drugs implicated in causing admissions included low dose aspirin, diuretics, warfarin, and non-steroidal antiinflammatory drugs. ${ }^{16}$ In the study by Davies et al most frequently implicated drugs were opioid analgesics, diuretics, systemic corticosteroids, anticoagulants and antibiotics and the most frequent causative drugs relative to usage were anticoagulants (warfarin). ${ }^{17}$ These studies are in accordance with our study, that anticoagulants being one of the most commonly involved drugs.

In our study, data related to type of ADRs were in accordance with the data given by Munir et al and Davies et al study, where majority of reactions were of type A. ${ }^{16,17}$ The proportion of patients presenting with severe ADRs (41.9\%) were higher than other studies (by Raut et al and Sriram et al) which might be due to the fact that in our study majority of patients were indoor patients and were more likely to be suffering from severe ADRs. ${ }^{12,14}$ Majority of patients $(98.4 \%)$ required hospitalization, which was similar to the trend seen in study by Mukesh Kumar B, and Prajapati et al. ${ }^{11,18}$

We used WHO causality scale for causality assessment and found that probably related were higher as compared to definitely related, then found the possibly related numbers and finally few were unlikely related.

The clinical events of ADRs reported in our study is comparable with the results of studies conducted in other hospitals. Data obtained from this research will be helpful for clinicians regarding careful selection of drugs like oral anticoagulants and ant diabetic drugs. Much emphasis should be given on part of physicians for reporting each and every ADR they come across, as patients admitted in any tertiary care hospitals are exposed to various group of drugs.

Our study was comparable to the studies done by Rout et al and Prajapati et al in terms of fatal outcomes but differ in terms of those who have recovered. ${ }^{11,12}$ These differences are due to the variable loss of patients to follow-up, non uniform selection criteria of patients with varying contribution of inpatients and outpatients in various studies, and non uniform studies method with some being retrospective and others prospective.

From this study it was finally concluded that adverse drug reactions have been known to cause significant morbidity and mortality for centuries. Drug toxicity is a major limitation in providing health care to patients at a global level. It affects patient's recovery as well as cause an economic burden on the patients as well as on the health care establishment. They should be considered in the differential diagnosis of a wide range of conditions as any bodily system can be affected and any disease process mimicked. It is essential that all involved medical professionals have some knowledge of the potential adverse effects of medicines, as key to appropriate management of ADRs is prompt recognition that the patient's new symptoms and signs may be drug related. 
One of the goals of ADR research is to alert physicians about the preventability of many ADRs.

\section{CONCLUSION}

Our study revealed that ADRs are frequent and are easily recognized in clinical practice and are mostly preventable. ADRs are ranked from the fourth to sixth leading cause of death in US. In our study type A $(97.7 \%)$ reactions were constituting the most, and most of the events occurred after prescriptions $(98.4 \%)$ by physicians. This suggests that most ADRs are due to the use of drugs with unavoidably high toxicity for example, warfarin often results in bleeding. It also shows that careful drug monitoring in hospitals may leads to a reduction of many of these ADRs, suggesting that some type A ADRs may be due to inadequate monitoring of therapies and doses. Prevention strategies should target the prescribing and monitoring stages. Interventions focused on improving patient adherence with prescribed regimens and monitoring of prescribed medications also may be beneficial. It is necessary to create more awareness to curb irrational poly-pharmacy which helps in prevention and an accurate diagnosis of the reactions. There is a need for increasing the knowledge and awareness to improve the reporting rate. While our results must be viewed with some circumspection because of the small biases in the sample, these data suggest that ADRs represent an important clinical issue. This study will aid the development of interventions to reduce the impact of ADRs in hospital in-patients.

\section{ACKNOWLEDGEMENTS}

Authors are thankful to Principal, Indira Gandhi Medical College, Shimla for providing basic facilities to carry out the study. Authors gratefully acknowledge the participation of all the patients in the study.

Funding: No funding sources

Conflict of interest: None declared

Ethical approval: The study was approved by the Institutional Ethics Committee

\section{REFERENCES}

1. Loke YK. Assessing the benefit- harm balance at the bedside. Br Med J. 2004;329;7-8.

2. World Health Organization. Technical Report Series 498. World Health Organization: Geneva, 1972.

3. Rawlins MD, Thompson JW. Pathogenesis of adverse drug reactions. In; Davies DM, ed. Textbook of adverse drug reactions. Oxford: Oxford University Press, 1977: 10.

4. Edwards IR, Aronson JK. Adverse drug reactions: definitions, diagnosis and management. Lancet. 2000;356:1255-9.

5. Pirmohamed M, Breckenridge AM, Kitteringham NR, Park BK. Adverse drug reactions. BMJ. 1998;316:1295-8.
6. Einarson TR. Drug-related hospital admissions. Ann Pharmacother. 1993;27:832-40.

7. Bates DW, Cullen DJ, Laird N, Petersen LA, Small SD, Servi D, et al. Incidence of adverse drug events and potential adverse drug events. Adverse drug event prevention study group. JAMA. 1995;274:2934.

8. Bates DW, Spell N, Cullen DJ, Burdick E, Laird N, Petersen LA et al. The costs of adverse drug events in hospitalized patients. Adverse drug events prevention study group. JAMA. 1997;277:307-11.

9. Lazarou J, Pomeranz BH, Corey PN. Incidence of adverse drug reactions in hospitalized patients: a meta-analysis of prospective studies. JAMA. 1998;279:1200-5.

10. Wenchen KW, Nicholas P. Evaluation of outpatient adverse drug reactions leading to hospitalization. Am J Health Syst Pharma. 2003;60:251-4.

11. Prajapati K, Desai M, Shah S, Panchal J, Kapadia J, Dikshit R. An analysis of serious adverse drug reactions at a tertiary care teaching hospital. Perspect Clin Res. 2016;7(4):181-6.

12. Raut A, Diwan A. Incidence, severity and financial burden associated with adverse drug reactions in medicine inpatients. Asian J Pharm Clin Res. 2011;4:2107-11.

13. Onder G, Pedone C, Landi F, Cesari M, Della Vedova C, Bernabei R, et al. Adverse drug reactions as a cause of hospital admissions: results from the Italian Group of pharmacoepidemiology in the elderly (GIFA). J Am Geriatr Soc. 2002;50:1962-8.

14. Sriram S, Ghasemi A, Ramasamy R, Devi M, Balasubramanian R, Ravi TK, et al. Prevalence of adverse drug reactions at a private tertiary care hospital in south India. $\mathbf{J}$ Res Med Sci. 2011;16(1):16-25.

15. Suh DC, Woodall BS, Shin SK, Hermes-De Santis ER. Clinical and Economic Impact of Adverse Drug Reactions in Hospitalized Patients. Ann Pharmacother. 2000;34:1373-9.

16. Pirmohamed M, James S, Meakin S, Green C, Scott AK, Walley TJ, et al. Adverse drug reactions as cause of admission to hospital: prospective analysis of 18820 patients. Br Med J. 2004;329:15-9.

17. Davies EC, Taylor S, Williamson PR, Mottram DR, Pirmohamed M. Adverse Drug Reactions in Hospital In-Patients: A Prospective Analysis of 3695 PatientEpisodes. PLoS ONE. 2009;4(2):4439

18. Vora MB, Trivedi HR, Shah BK, Tripathi CB. Adverse drug reactions in inpatients of internal medicine wards at a tertiary care hospital: A prospective cohort study. J Pharmacol Pharmacother. 2011;2(1):21-5.

Cite this article as: Singh R, Mokta JK, Mokta K, Thakur S, Bhawani R, Ramesh. A study on clinical profile of patients presenting with adverse drug reaction: a hospital based prospective observational study. Int J Basic Clin Pharmacol 2019;8:2140-4. 